\title{
On the observation of magnetic events on broad-band seismometers
}

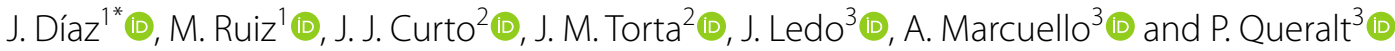

\begin{abstract}
The objective of this contribution is to get new insights into the effects of magnetic field variations of natural and anthropogenic origin on broad-band seismic stations. Regarding natural sources of magnetic perturbations, we have investigated if the Sudden Storm Commencements (SSC) cataloged during the 24th solar cycle (2008-2019) can be systematically identified in broad-band seismic stations distributed worldwide. The results show that the 23 SSC events with a mean amplitude above $30 \mathrm{nT}$ and most of those with lower energy but still clearly identified in the magnetometer detection network can be observed at broad-band stations' network using a simple low-pass filter. Although the preliminary impulse of those signals is usually stronger at stations located at high latitudes, major SSC are observed at seismic stations distributed worldwide. Regarding anthropogenic sources, we focus on the short period seismic signals recorded in urban environments which are correlated with the activity of the railway transportation system. We have analyzed collocated measurements of electric field and seismic signals within Barcelona, evidencing that significant changes in the electric field following the activity of the transportation systems can be attributed to leakage currents transmitted to the soil by trains. During space weather events, electric currents in the magnetosphere and ionosphere experience large variations inducing telluric currents near the Earth surface, which in turn generate a secondary magnetic field. In the case of underground trains, leakage currents are transmitted to the soil, which in turn can result in local variations in the magnetic field. The observed signals in modern seismometers can be related to the reaction of the suspension springs to these magnetic field variations or to the effect of the magnetic field variations on the force transducers used to keep the mass fixed.
\end{abstract}

Keywords: Sudden Storm Commencements, Anthropogenic sources of magnetic noise, Seismic instrumentation

\section{Introduction}

This contribution presents examples of electromagnetic signals, both from natural and anthropogenic origins, which are recorded regularly by permanent and temporary broad-band seismometers. The effect of magnetic events on seismic signals is known since the beginning of modern broad-band instruments and related to the mechanism of the signal generation in the devices (Wielandt 2002). A limited number of contributions have studied this effect, focusing on its suppression to enhance the identification of signals in the normal mode band

\footnotetext{
*Correspondence: jdiaz@ictja.csic.es

1 Geosciences Barcelona, CSIC, c. Solé Sabarís sn, 08028 Barcelona, Spain Full list of author information is available at the end of the article
}

(0.3-3 mHz) (Forbriger 2007; Forbriger et al. 2010). Our aim here is to analyze if these magnetic perturbations are a widespread feature affecting systematically seismic instruments distributed worldwide and to discuss the mechanism explaining the detection of magnetic field variation in broad-band sensors.

Different electromagnetic signals of natural and manmade origin can potentially affect the seismic instruments, including magnetic storms, auroral electrojets, lightening during meteorological storms, magnetic fields produced by local supply currents, perturbations due to the passage of moving magnetic or electrical elements or leakage currents associated to transportation systems. We will focus here on two kinds of magnetic signals, the Sudden Storm Commencements (SSC) often preceding 
the arrival of large magnetic perturbations due to solar storms and the effect of electromagnetic fields associated with the activity of public transportation systems within the city of Barcelona. In the first case, we will show that large SSCs are recorded regularly at global and local seismic networks distributed worldwide, confirming previous observations. In the second case, we will document, using collocated electric and seismic sensors, that the activity of underground railway and surface tramway results in an electrical field that can be recorded at distances of hundreds of meters, generating a perturbation that dominates the seismic spectra for frequencies below $10 \mathrm{mHz}$.

\section{SSC recordings on broad-band seismometers}

Sudden commencements (SC) are defined as abrupt increases of the horizontal component of the Earth magnetic field due to the compression of the magnetosphere, which may be followed or not by a magnetic storm (Park et al. 2015). Following the initial onset, SC signals show an increase of the horizontal magnetic intensity $(\mathrm{H})$ which can last from 1 to $10 \mathrm{~min}$ but is usually limited to 3-4 $\mathrm{min}$ (Maeda et al. 1962). It has been proposed that the sudden increase of the magnetic field should be designed by the general term sudden commencement (SC), which can be named as SSC if it is followed by a magnetic storm or as a sudden impulse (SI) if it is not (Curto et al. 2007). However, the term SSC is usually used to refer to the two subcases. The amplitude of the magnetic field during SSC episodes vary quickly from 10 to $15 \mathrm{nT}$ to several hundreds of nanoteslas (Nishida 1978), making them a good candidate to be detected in different kind of instruments. Due to its nature, SSC are global geophysical phenomena which can be detected everywhere on Earth, although the primary impulses are stronger in high latitudes and can produce steep responses in the magnetograms. The origin of SSC is related to sudden increases in the solar wind dynamic pressure. According to Araki's model of SSCs (Araki 1977, 1994), the magnetic perturbation is attributed to the combination of two current contributions: (i) one due to the increased pressure of the magnetopause when the hydromagnetic wave hits the magnetosphere; and (ii) the other as a consequence of the conducting ionosphere reaction to a transient dusk-to-dawn electric field transmitted from the compressional wavefront through the geomagnetic field lines down to the polar upper atmosphere. The first one is not only maximum at the geomagnetic equator, but it is also noted in the low- and middle-latitude north component of the ground magnetic records. On the contrary, the second contribution is produced by two successive current vortices with reversed polarity which are observed to develop in the polar cap ionosphere, moving toward the flanks of the polar cap starting from a location closer to noon (e.g., Marsal et al. 2017).

Following the arrival of the magnetic perturbations generated by solar storms, the magnetospheric and ionospheric currents experience large variations, which in turn create secondary magnetic fields, that are systematically recorded by magnetometers. These variations produce the so-called Geomagnetic Induced Currents (GIC) in conductors operating at or near the surface of the Earth (e.g., Ngwira et al. 2015; Pulkkinen 2015). Although the larger magnetic field variations associated with those events are observed at high latitudes, GIC are also recorded at mid-latitudes during major storms (e.g., Torta et al. 2012). The monitoring of GIC is of great economical interest, as they can result in high-voltagepower transformers' degradation, increase the corrosion of pipelines steel or disturb seafloor fiber optics' systems (e.g., Oughton et al. 2017).

Since 1976, the SSC determination lists are compiled by the Service of Rapid Magnetic Variations held by the Observatori de l'Ebre, and distributed by the International Service of Geomagnetic Indices (http://isgi.unist ra.fr). The detection of those signals is based on the visual recognition of the signals in the magnetograms from five selected low-latitude observatories, although some automatic detection methods have been proposed in the last decade (Khabarova et al. 2006; Segarra and Curto 2013). The SSC catalog qualifies each event according to the clarity of its identification at the reference observatories and provides the mean amplitude value for each event. The events with a very sharp change of rhythm, large amplitude values, and remarkably morphology are classed as "unmistakable" event in the catalog.

\section{SSC observations on global seismic networks}

To show an example of seismic records contemporary to SSCs, we will first discuss the 7th September 2017 event, reported in the IAGA Bulletin with a mean amplitude of $31.9 \mathrm{nT}$. We have selected a group of 145 broad-band seismic stations from some of the main worldwide-scale seismic networks, including the Global Seismograph Network (Albuquerque Seismological Laboratory ASL/USGS 1988), the IRIS/IDA seismic network (Scripps Institution of Oceanography 1986), Geoscope (Institut De Physique Du Globe De Paris 1982) and Geofon (GEOFON Data Centre 1993). The raw seismic data have been corrected for the instrumental response and expressed as ground acceleration. This procedure, common in seismological practice, removes the effect of the recording instrument, allowing measuring the effective movement of the soil. Data processing is very simple, as it only includes the application of a low-pass filter with a corner frequency of 
$0.01 \mathrm{~Hz}$ to suppress the high-frequency signals related to oceanic waves and human activities (e.g., Díaz 2016). We identify a detection when a long period pulse is observed at the time of the reported SSC, clearly outstanding the previous minutes of the filtered signal. For this example, the SSC can be identified in around 55\% of the available sites.

As observed in Fig. 1, the stations showing a clear signal are not limited to higher latitudes but spread all over the world. Although there are some outliers, larger amplitudes are mostly recorded, as expected, at high latitudes.

Figure 2 provides more details on the signals recorded for the same event at stations located at different latitudes, including the Arctic Circle, the tropics, midlatitude southern hemisphere and Antarctica, hence denoting the widespread character of the recordings. In each case, we show the horizontal magnetic intensity $(\mathrm{H})$ as recorded by the closest geomagnetic observatory of the INTERMAGNET network and the seismic acceleration after applying a $0.01-\mathrm{Hz}$ low-pass filter. The lower panels show the spectrograms, a diagram showing the temporal evolution of the frequency content of the filtered signals. The spectrograms show that an increased energy level can be identified for at least $45 \mathrm{~min}$ after the SSC. Hence, broad-band seismometers do not only record the SSC but are sensitive to the whole magnetic storm.

As stated in "Introduction" section, our objective in this work has been to verify if SSC signals are recorded systematically at broad-band seismic stations distributed worldwide. To get a representative database, we
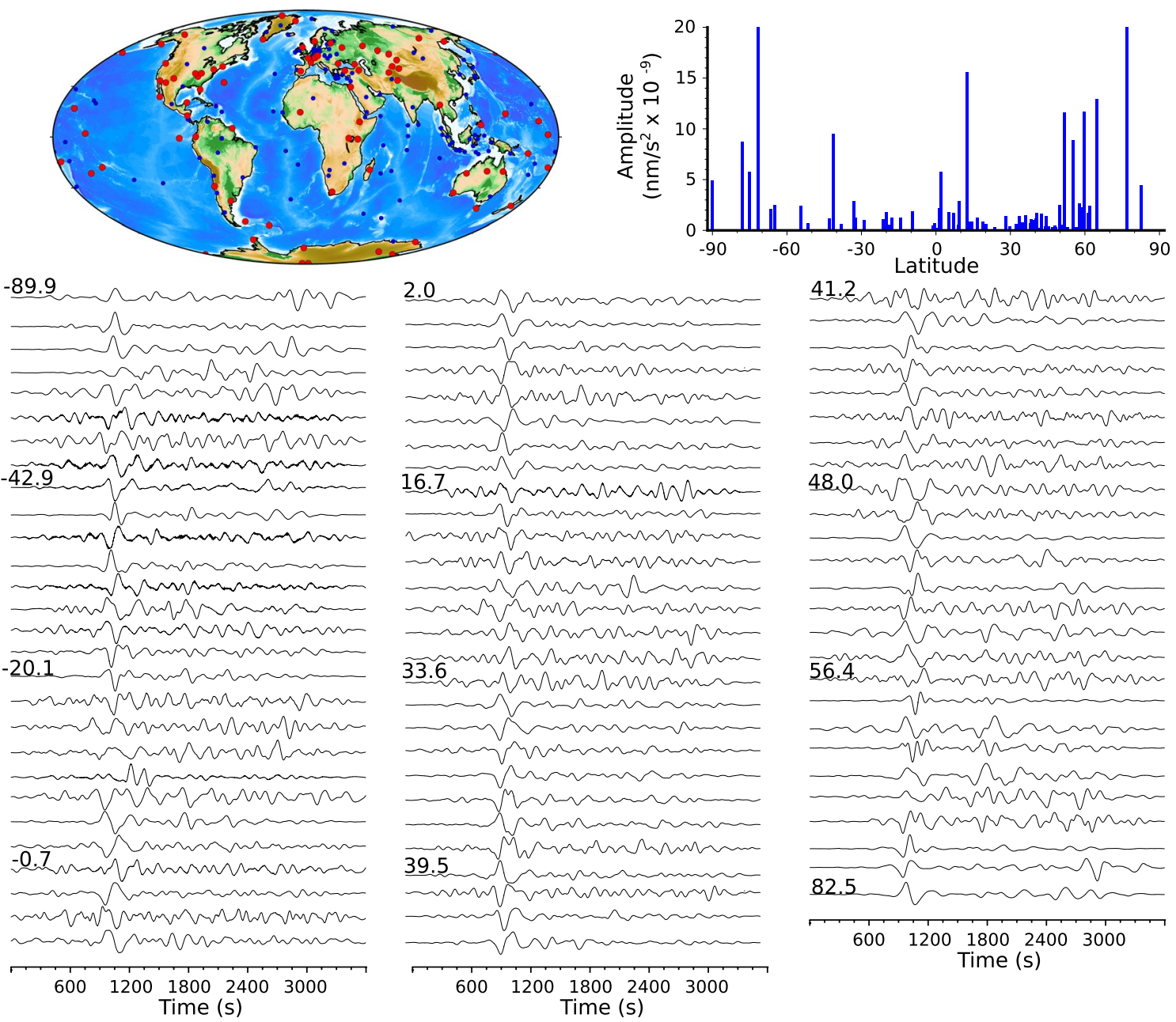

Fig. 1 Seismograms during the 2017/09/07 SSC event. Seismograms show 1 h of the vertical seismic acceleration, as recorded by the 82 broad-band stations distributed worldwide with positive identifications. The traces are normalized in amplitude after low-pass filtering at $0.01 \mathrm{~Hz}$ and ordered by latitude (labels show reference latitudes). The upper left panel map shows with red dots the sites with clear seismic recording of the SSC event and with black dots, the stations without clear evidences. Upper right panel shows the peak amplitude of the seismic signals as a function of latitude 

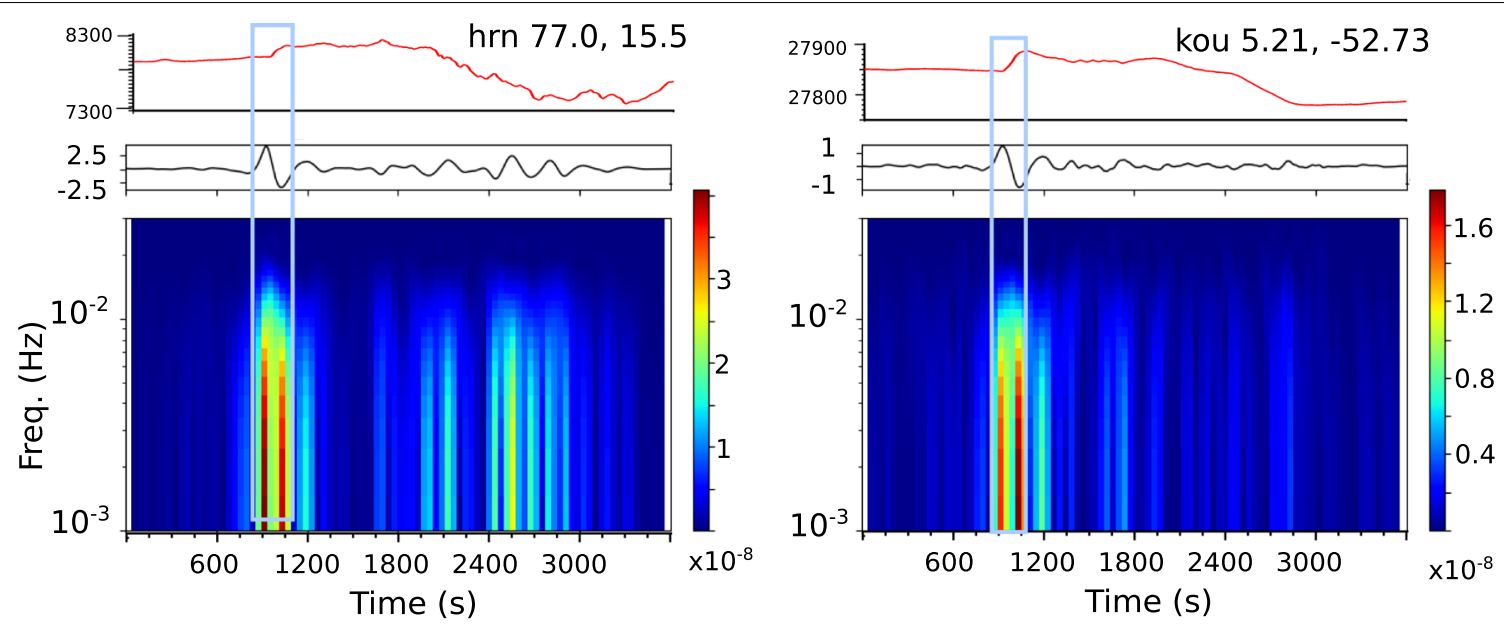

82.5033, -62.35

Alert, N.W.T., Canada

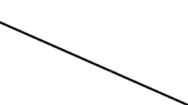

$5.11,-52.64$

Montagne Pères, Guyane

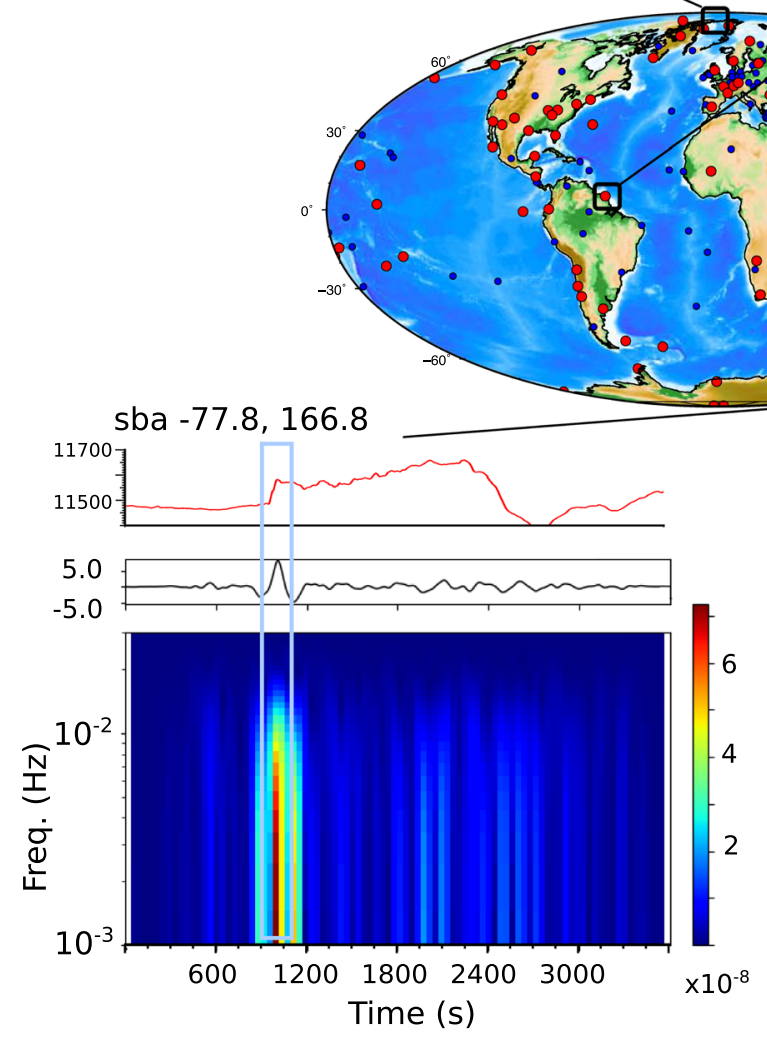

$-77.85,166.75$

Scott Base, Antarctica

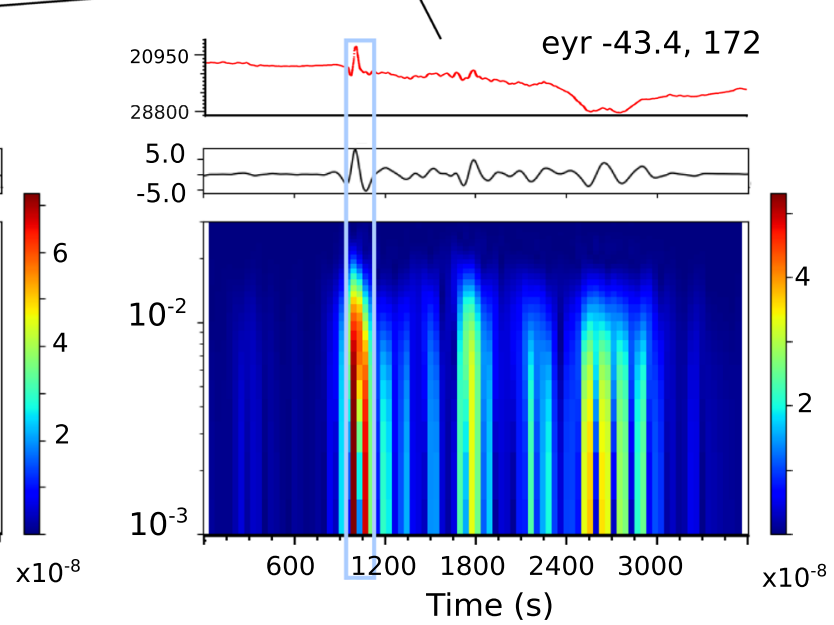

$-41.31,174.70$

South Karori, New Zealand

Fig. 2 Examples of 2017/09/07 SSC event recordings at seismic stations located at different latitudes. Data spans 1 h, starting 15 min before the onset of the SSC event. For each site, the upper panel shows in red the horizontal magnetic intensity $(\mathrm{H})$ at the closest magnetic stations of the INTERMAGNET network. Middle panel shows the low-pass filtered $(0.01 \mathrm{~Hz})$ seismic acceleration and lowermost panel shows the spectrogram of the filtered seismic signal. Amplitude scale for the seismic signals is in $\mathrm{m} / \mathrm{s}^{2} \times 10^{-9}$ 
have inspected all the SSC with mean amplitudes above $30 \mathrm{nT}$ and the events of lower amplitude but qualified as "unmistakable" in the catalog during the 24th solar cycle, spanning between 2008 and 2019. For each of the 34 events selected, we have recovered the data of the 145 seismic stations described above and inspected the occurrence of the SSC signals. We have inspected the seismic horizontal components, but in a large majority of the cases the SSC-related signal is not visible, probably because the higher level of noise affecting the horizontal components at low frequencies, mostly related to tilt effects, masks the eventual recording of small signals as those related to SSCs. Therefore, we have focused on the analysis of the vertical seismic components.

As reported in Table 1, all major SSC events in the IAGA catalog can be identified in global-scale seismic networks, with a percentage of observations ranging between 10 and $65 \%$ of the locations, with a mean value of $48 \%$. Figure $3 \mathrm{a}$ shows the relationship between magnetic amplitudes and the number of detections in the seismic records, which has a strong coincidence, although some outliers can still be identified. If only SSC

Table 1 SSC events inspected in this study

\begin{tabular}{|c|c|c|c|c|c|c|c|c|}
\hline Date & Hour & MDUR & MAMP & Codes & Event type & \#Obs & $\%$ & Coincident earthquakes \\
\hline 04/08/2010 & $10: 18: 48$ & 4.8 & 73.5 & 11111 & SSC & 21 & 14 & 5.5 Tonga 10:07 \\
\hline 04/06/2011 & $20: 44: 00$ & 5.6 & 39.7 & 22222 & SSC & 37 & 26 & 5.2 Papua 20:42 \\
\hline 09/09/2011 & $12: 42: 00$ & 4 & 37 & 32332 & SSC & 49 & 34 & \\
\hline 26/09/2011 & $12: 34: 36$ & 3.2 & 42.1 & 33332 & SSC & 53 & 37 & \\
\hline 24/10/2011 & 18:31:00 & 3.2 & 38.8 & 32332 & SSC & 56 & 39 & \\
\hline $24 / 01 / 2012$ & 15:03:00 & 4.8 & 44.7 & 22333 & SSC & 53 & 37 & \\
\hline 08/03/2012 & 11:03:00 & 4.2 & 48.8 & 22222 & SSC & 41 & 28 & \\
\hline $12 / 03 / 2012$ & 09:14:00 & 5 & 51.9 & 22222 & SSC & 49 & 34 & \\
\hline $14 / 07 / 2012$ & 18:09:00 & 3.6 & 41.1 & 22222 & SSC & 54 & 37 & 6.1 Kuril 17:36 \\
\hline 03/09/2012 & $12: 13: 00$ & 4.8 & 31.3 & 10221 & SSC & 38 & 26 & \\
\hline $17 / 03 / 2013$ & $05: 59: 48$ & 3.2 & 31.2 & 22222 & SSC & 56 & 39 & \\
\hline $24 / 05 / 2013$ & 18:09:48 & 4.2 & 32.7 & 22222 & SSC & 52 & 36 & \\
\hline 02/10/2013 & 01:54:36 & 3.4 & 42.2 & 23322 & SSC & 52 & 36 & 5.7 W Somalia 01:06 \\
\hline 08/10/2013 & $20: 20: 24$ & 4.6 & 50.4 & 32333 & SSC & 56 & 39 & \\
\hline $27 / 02 / 2014$ & 16:50:00 & 4.4 & 34.7 & 22222 & SSC & 27 & 19 & \\
\hline $12 / 09 / 2014$ & $15: 53: 30$ & 4.4 & 46.1 & 22222 & SSC & 69 & 48 & 5.1 Indon. 15:41 \\
\hline $23 / 12 / 2014$ & $11: 14: 24$ & 3.6 & 49.6 & 22333 & $\mathrm{SI}$ & 80 & 55 & \\
\hline $17 / 03 / 2015$ & 04:45:00 & 2.6 & 39.9 & 33333 & SSC & 83 & 57 & \\
\hline $21 / 06 / 2015$ & $16: 44: 00$ & 7.2 & 35.3 & 22222 & SSC & 35 & 24 & \\
\hline 22/06/2015 & 18:33:00 & 2.6 & 88.8 & 33333 & SSC & 92 & 63 & \\
\hline 19/07/2016 & 23:51:00 & 4.2 & 40.1 & 22222 & SSC & 63 & 43 & \\
\hline 26/01/2017 & 08:15:00 & 4.2 & 11.5 & 33333 & SSC & 25 & 17 & 5.1 Japan 8:06 \\
\hline 04/05/2017 & $21: 23: 00$ & 5.2 & 21.7 & 33332 & $\mathrm{SI}$ & 45 & 31 & \\
\hline 16/07/2017 & 05:59:00 & 4.6 & 51.1 & 33333 & SSC & 93 & 64 & \\
\hline 06/09/2017 & $23: 43: 00$ & 4.2 & 20.3 & 33332 & SSC & 63 & 43 & \\
\hline 07/09/2017 & 23:00:00 & 2.6 & 31.9 & 33330 & SSC & 83 & 57 & \\
\hline 27/11/2017 & $14: 42: 00$ & 8 & 16.7 & 22333 & $\mathrm{SI}$ & 14 & 10 & - \\
\hline 08/01/2018 & 06:46:00 & 5.6 & 20.7 & 33333 & SSC & 57 & 39 & \\
\hline 09/03/2018 & 18:06:00 & 5.8 & 16.4 & 33333 & SSC & 17 & 12 & 5.4 N. Zeal 18:02 \\
\hline 20/04/2018 & $00: 21: 00$ & 6 & 24.3 & 33333 & SSC & 37 & 26 & 5.3 Tonga 23:59 \\
\hline 24/03/2019 & 21:51:00 & 4.2 & 10.4 & 31333 & SI & 25 & 17 & \\
\hline 26/05/2019 & $22: 14: 00$ & 5.4 & 15.6 & 33332 & SSC & 13 & 9 & 8.0 Peru 07:41 \\
\hline 08/07/2019 & 19:22:00 & 5.6 & 23.8 & 33333 & SSC & - & - & 5.9 Indon. $18: 52$ \\
\hline 04/08/2019 & 07:16:00 & 5.6 & 11.9 & 33332 & SI & 24 & 17 & \\
\hline
\end{tabular}

Codes refer to the IAGA catalog. Columns 7 and 8 show the number and percentage of positive identifications. Last column reports large earthquakes (mag $>5$ ) with origin time within less than $1 \mathrm{~h}$ before the corresponding SSC

MDUR mean SC duration or rise-time in minutes, MAMP mean amplitude in $\mathrm{nT}$ 

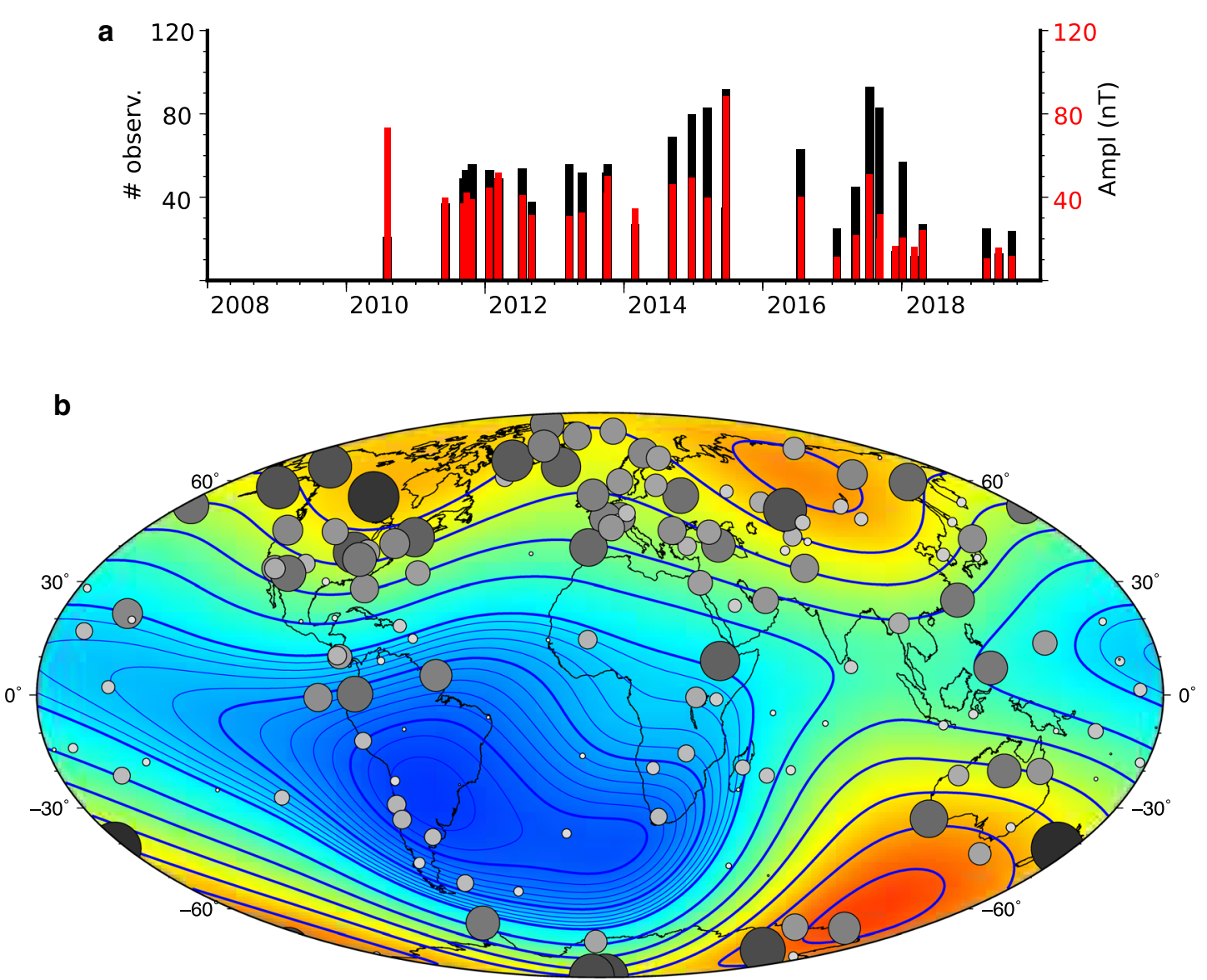

number of observations per site

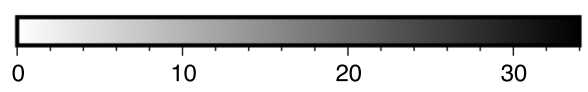

Total intensity $(\mathrm{nT})$

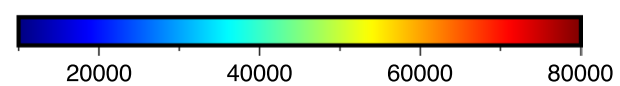

Fig. 3 Magnetic amplitude of the SSC events vs. seismic observations. a Mean amplitude of the significant SSC events during the 24th solar cycle (red bars) compared with the number of observations of each event in the broad-band stations (black bars). b Total magnetic intensity (NCEl Geomagnetic Modeling Team and British Geological Survey 2019) for year 2018 compared to the number of SSC observations for each investigated broad-band seismic station. F isolines are shown every $1000 \mathrm{nT}$ below 35,000 nT and every $5000 \mathrm{nT}$ above this value to better constrain the SAA anomaly. The size and gray saturation of the circles represent the number of observations at each seismic site, with small white dots representing seismic sites without observations

events with reported mean amplitude above $40 \mathrm{nT}$ are considered, the number of broad-band stations where SSC can be identified ranges between 50 and 95 , that is, $35 \%$ to $65 \%$ of the inspected sites. The SSC events with larger number of detections on broad-band seismometers are those occurring on the 16th July 2017, the 7th September 2017, the 17 March 2015 and the 23 December 2014, all of them detected in more than 80 seismic stations and presenting mean amplitudes between 32 and $52 \mathrm{nT}$ (Table 1).

Figure $3 \mathrm{~b}$ shows the number of SSC observations during the 2008-2019 period in each of the investigated sites. As discussed previously for a particular example, the observation of SSC is not limited to high latitudes. The stations detecting a large majority of the SSC events are those located near the South pole and in the northern part of Canada, but many stations in mid-latitudes of the northern hemisphere have detected more than 50\% of the 34 SSC inspected events, while stations in SouthAmerica and the southern part of Africa show the lowest number of detections. As observed at Fig. 3b, the region with low number of seismic detections of SSC events matches closely the South-Atlantic Anomaly (SAA), a very weak magnetic intensity minimum localized in the 
South Atlantic and due mainly to the contribution of the quadrupole component of the main field (e.g., Olsen et al. 2007).

On the other hand, most of the sites with positive identifications are located near coastlines, but the pattern is not clear, as there are positive cases in locations far from the coast as well as there are a relevant number of locations in islands within large oceanic basins without positive identifications.

We have checked the occurrence of large earthquakes which could produce surface waves that could be misinterpreted as SSC. Table 1 also reports in the last column the earthquakes of magnitude greater than 5 and origin time within less than $1 \mathrm{~h}$ before the SSC. As we require the seismic pulse at the time of the SSC to be clearly larger than the previous signals, the possibility of misinterpreting a surface wave as SSC is very low. It is more probable in fact that SSCs occurring during the propagation of the surface waves of large earthquakes get masked by them. This is the case for the 08/07/2019 SSC event, occurring 30 min after a 5.9 magnitude event in Indonesia, for which we have not identified any clear record. The same feature can explain the low number of observations of the $26 / 01 / 2017$ and 08/03/2018 SSCs, both occurring some minutes after significant earthquakes.

\section{Observations in local networks}

To better illustrate the characteristics of the seismic recording of magnetic events and to analyze its robustness, we have inspected the signals recorded at local networks of different spatial scales. We have inspected the collocated sensors at station QSPA near the South Pole, the Norwegian Seismic Array Network, located in a highlatitude region (southern Norway), and the ICGC network in NE Iberia, covering a mid-latitude region.

\section{Southern pole: QSPA station}

Station QSPA is located in the South Pole Remote Earth Science Observatory, at $8 \mathrm{~km}$ from the geographic South Pole $\left(89.929^{\circ} \mathrm{S}, 144.438 \mathrm{E}\right)$. The station, belonging to the IU network (Albuquerque Seismological Laboratory (ASL)/USGS 1988), sits over a glacier $2.5 \mathrm{~km}$ thick and it is considered one of the quietest seismic stations in the world. Its equipment includes three broad-band instruments installed in boreholes at depths of $270 \mathrm{~m}$ (KS54000), 255 m (CMG3-T) and 146 m (CMG3-T) and two additional seismic instruments installed in a cylindrical vault with the floor $3 \mathrm{~m}$ below the surface of the snow (STS-2.5 and STS-1V/VBB). The boreholes, excavated in solid ices, are dry and not cased. This site is an excellent choice to compare how the SSC are recorded by different seismic sensors, as its location in the South Pole makes it very sensitive to small magnetic field variations and because it is free from anthropogenic seismic noise. 24 out of the 34 SSC investigated in this study have been clearly identified in the seismic data recorded at this site.

Figure 4 shows the magnetogram recorded at the magnetic station SBA, located at the Scott Base in Antarctica $\left(-77.5^{\circ} \mathrm{S}, 166.78^{\circ} \mathrm{E}\right)$ and the seismic records of the 23rd December 2014, when a strong SSC event with a reported mean amplitude near $50 \mathrm{nT}$ happened. The seismic traces are represented normalized in amplitude in Fig. 4a and using a common amplitude scale in Fig. 4b. In both cases, the data have been corrected from its instrumental response and low-pass filtered below $0.01 \mathrm{~Hz}$. As it can be observed, the different traces have a similar waveform but differ strongly in amplitude. The two deeper sensors, located at 270 and $254 \mathrm{~m}$, differ in amplitude by a factor of 3 , with larger amplitudes in the deeper sensor. The sensor at $146 \mathrm{~m}$ depth has an amplitude almost 5 times larger than the same instrument buried at $254 \mathrm{~m}$. This fact is remarkable, as electromagnetic signals are expected to be attenuated with depth following an exponential law. The two sensors installed in a vault close to the snow surface have opposite polarizations and the trace recorded by the STS-1V has an amplitude with an order of magnitude lower than the rest. As the data have been corrected for the instrument responses, these large differences are unexpected. We have verified that these waveform differences between sensors remain stable for all the SSC-related signals during the analyzed time interval (Additional file 1: Figure S1), despite the maximum amplitude of each event. Figure $4 \mathrm{c}$ shows the records at the same sensors of a 6.3 magnitude earthquake with epicenter in the Indonesia region, represented also in true amplitude. In this case, the data recorded at each sensor have the same amplitude once corrected by its instrumental response. Therefore, we must conclude that the physical process explaining the recording of magnetic signals is not considered in the instrument response, which should be modified to account for this effect. This fact confirms that, if seismic sensors had to be used to quantify SSC events, an individual calibration for each instrument should be needed (Forbriger 2007).

\section{High latitudes: Norsar array}

Regarding the high-latitude network, we have inspected the data recorded at stations of the NORSAR PS27 array, covering an area of about $70 \times 70 \mathrm{~km}$ located $120 \mathrm{~km}$ north of Oslo in Southern Norway. As in the previous case, the response of each instrument is removed and data are filtered with a low-pass filter at $0.01 \mathrm{~Hz}$.

The data presented in Fig. 5 show not only that this SSC is clearly observed at the 7 stations, but also that significant differences do occur between sites located a few tens of kilometers apart. Amplitude normalized traces (Fig. 5, 

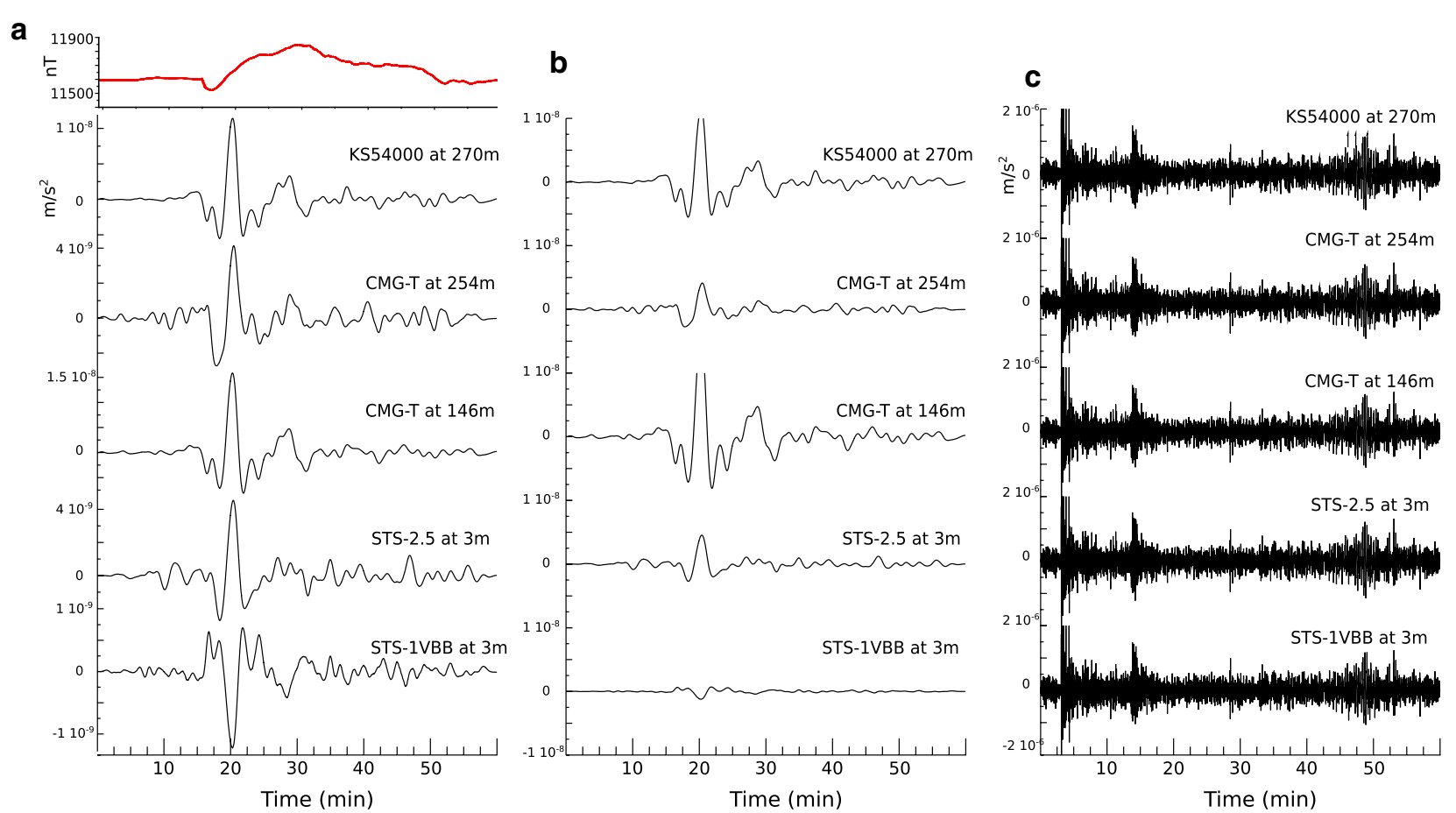

Fig. 4 Seismic signals at QSPA station (South Pole). a Top panel: magnetic field (H) recorded at the SBA magnetic observatory, located at the Scott Base (77.85० S, $\left.166.78^{\circ} \mathrm{E}\right)$. Bottom panel: seismic acceleration records during the 2014/12/23 SSC event at the different sensors of the QSPA site, represented in normalized amplitudes. b Same data represented using a common amplitude scale. c Seismic records of an M 6.3 earthquake with epicenter in Indonesia represented in true amplitude

left panel) show two families of traces, with opposite polarization. Stations NC602, NA001 and NC204 (top traces) share the same polarity, while NB201, NBO00, NC303 and NC405 have similar waveforms but opposite polarities. The inspection of the traces in true amplitude (Fig. 5 right panel) evidences large amplitude variations between neighboring stations, with sites $\mathrm{NC602}$ and NAO01 having the lowest amplitudes, while sites NBO00 and NC204 have values up to five times larger.

As in the discussion of the collocated sensors in QSPA site, these variations cannot be related to the location of the sites or the different models of sensors, as proven by the fact that the records of seismic events do not show polarity reversals or amplitude variations. This confirms that the SSCs records on broad-band seismometers are dependent on the sensitivity to magnetic variations of each particular sensor.

\section{Mid-latitudes: ICGC array}

Finally, we have checked the SSC observation in the regional, mid-latitude CA network (Institut Cartogràfic i Geològic de Catalunya 2000). The array is formed by 22 broad-band seismometers covering an area of about $32,000 \mathrm{~km}^{2}$ in NE Iberia, at latitudes ranging between $40^{\circ} \mathrm{N}$ and $42.5^{\circ} \mathrm{N}$. This case is of interest because only for three of the sites SSCs' events can be systematically identified in the seismic records. These sites, all of them in an area of $25 \times 30 \mathrm{~km}$ in or near the Ebro River delta, are EBR, located within the Observatori de l'Ebre and CBUD and CFAR both located in the Ebro River delta, in areas recently gained to the sea. As observed in Fig. 6, the signals related to SSC have large amplitude and better signal-to-noise ratio at CBUD and CFAR, are still clearly identified at site EBR and are not detected at site CMAS, located on the foothills of the Caro Mount, part of the Catalan Coastal Ranges.

Near the edge of the ocean, the abrupt change in conductivity can produce substantial enhancement of the electric field on the landward side. The so-called "coast effect" is taken into account in geomagnetic sounding studies of Earth conductivity and in the evaluation of the effects of magnetic storms on seafloor fiber optics telecommunication systems and power grids (e.g., Gilbert 2014; Pirjola 2013; Torta et al. 2017). The CA seismic stations detecting SSC events are located near to the Mediterranean coast. Other sites of the same network located close to the coast show a different degree of detection of SSC-related signals. Station CGAR shows three SSCrelated signals during the 2010-2019 period, while stations CPAL and CCAS do not show any event. Stations 

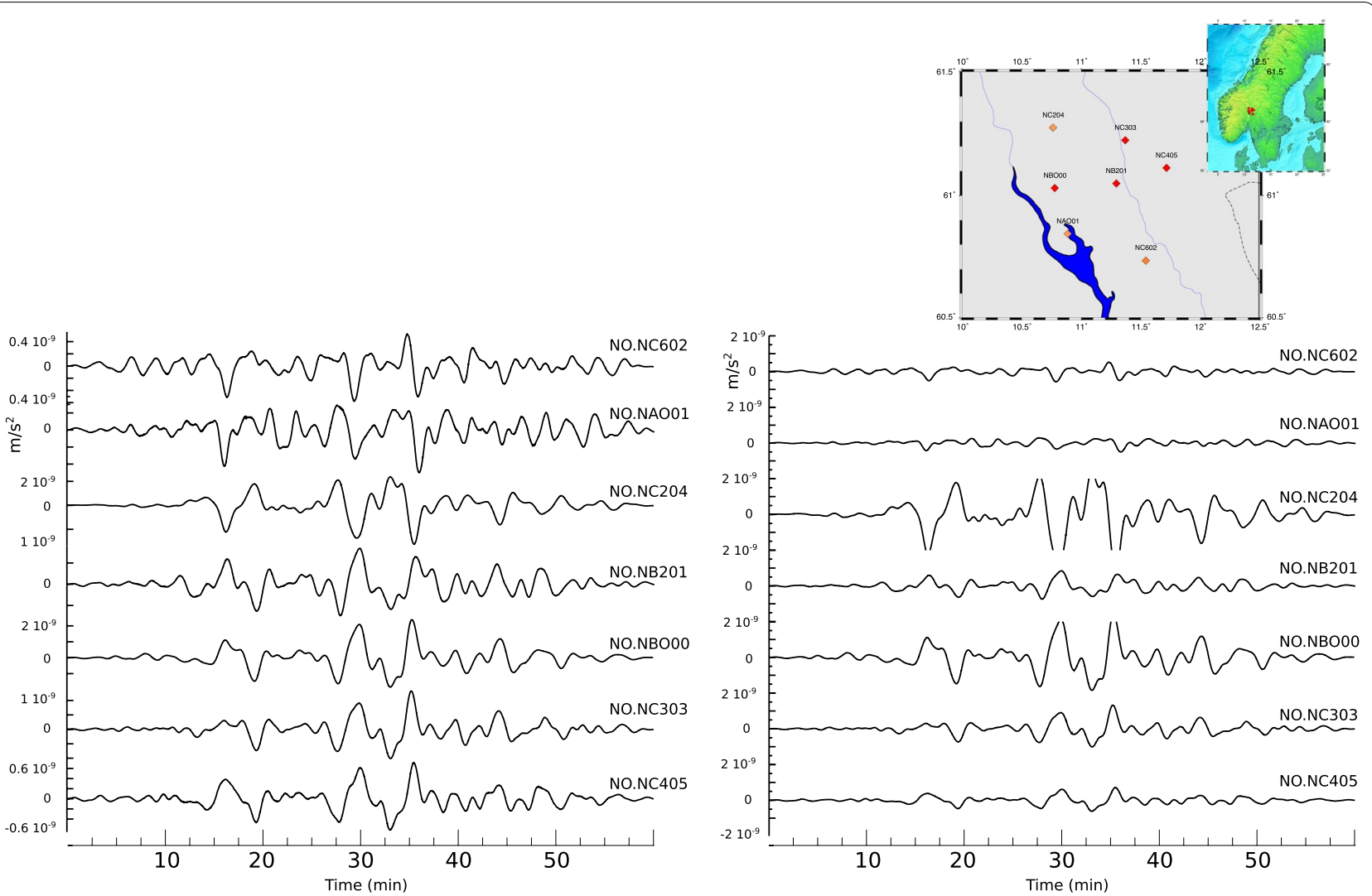

Fig. 5 Seismic records of magnetic events at high-latitude networks. Seismic acceleration recordings during the 2017/09/07 SSC event at stations of the Norsar Site array. Left panel: amplitudes normalized for each trace. Right panel: traces plotted using a common amplitude scale

of the WM network (San Fernando Royal Naval Observatory et al. 1996) located near the coast of the Balearic Islands and SE Iberia have also been inspected providing only a very limited number of positive identifications.

The difference in the amplitude of the SSCs seismic signals can be related to the geological materials at each site, which in turn affects the electrical conductivity of the ground (map onset in Fig. 6). CFAR and CBUD, the sites with maximum amplitude, are located over quaternary sand and silt terrains, where low electrical resistivity not exceeding $4 \Omega \mathrm{m}$ has been observed in the uppermost $50 \mathrm{~m}$ underlaying a thin $(3 \mathrm{~m})$ more resistive layer (Bellmunt et al. 2018). EBR, where the signal is clear but has smaller amplitude, lays over an alluvial fan formed by unconsolidated sedimentary materials, where resistivity is expected to be still low. Although resistivity measurement near the seismic site is not available, Bellmunt et al. (2018) have shown a clear increment of resistivity toward the inner part of the Ebro River, reaching values between 5 and more than $30 \Omega \mathrm{m}$ over the first $50 \mathrm{~m}$ of depth in the marginal area. On contrary, CMAS lays over Jurassic black dolomites with low electrical conductivity. The two sites were located in the Ebro River delta (CFAR and
CBUD); the sensitivity of the instruments to magnetic events can be enhanced by the large volume of marine saline intrusions documented in the area (Palanques and Guillén 1998). Therefore, it seems clear that there is a relationship between ground conductivity and sensibility of the broad-band sensors to magnetic effects.

\section{Low-frequency sources associated to anthropogenic sources}

Human activities, in particular in urban environments, generate electromagnetic field propagating in the solid earth and the ocean basins. The most important sources of man-made electromagnetic field are high-voltage direct current cables (HVDC) although significant contributions can arise from cell tower base antennas or leakage current related to transportation systems. We will focus here on the effect of these leakage currents near our recording site. DC electric railways (subway, tramway) produce magnetic fields both from the intended traction currents and from the stray currents leaking to the Earth, although the first ones are only relevant near the train (Lowes 2009). 


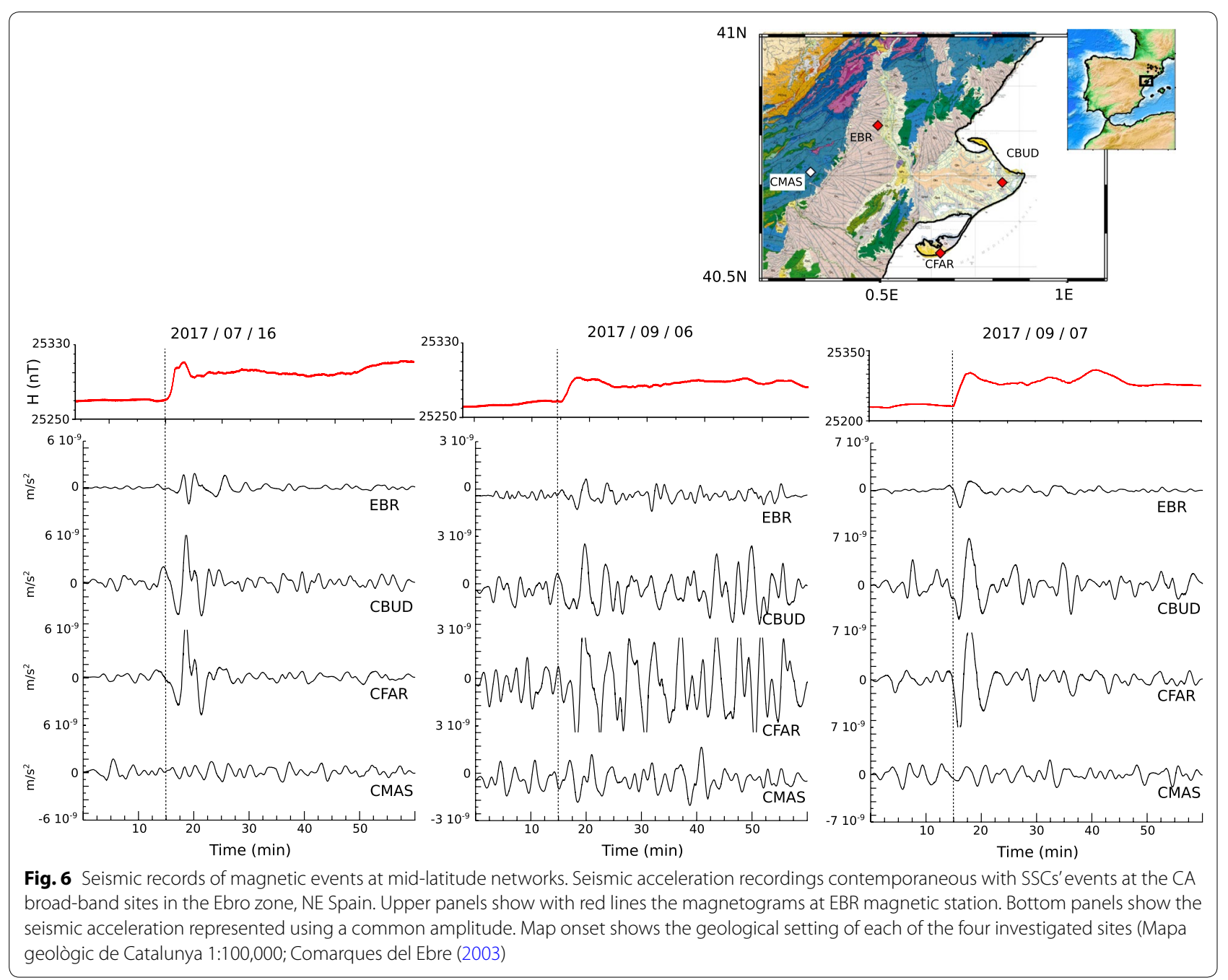

\section{Stray current associated to transportation systems}

Subway and tramway systems often use the running rail as a traction loop. As the insulation is not complete, part of the current flows into the earth, in what is known as stray or leakage currents. The study of these currents is of interest from an engineering point of view, as it results in electrochemical corrosion of metal structures close to the subway system. An updated review of the current distribution models can be found at Wang et al. (2018). However, the modeling of stray currents is difficult as all the metallic structures around the railway need to be considered, rail and rail-to-earth resistances can change locally and the grounding system can be more complex than the usually accepted resistor network model. This makes it problematic to realistically evaluate the intensity of the stray currents for a particular location.

The stray currents can produce electromagnetic disturbances that strongly affect magnetotelluric measurements at distances over tens of kilometers (de Pádua et al.
2002) and have even been used as a source to measure ground resistivity at distances around $16 \mathrm{~km}$ (Tanbo et al. 2003). As an example of the effect of these currents in different measuring systems, we can highlight that the leakage currents associated to the passage of TGV trains at distances of 1-3 km have been identified as noise sources in the CERN Large Electron Positron collider (LEP) near Geneva (Bravin et al. 1998).

\section{Observation of leakage currents on broad-band seismometers}

Díaz et al. (2017) analyzed the sources of background seismic noise for a broad-band station located within the city of Barcelona, and noted a periodic change in the amplitude of the seismic amplitude clearly correlated with the subway system. The subway system at Barcelona works from 05:00 to 23:59 (local time) Monday to Thursday, 05:00-02:00 on Friday and continuously from 05:00 Saturday until 00:00 on Sunday. A tramway line, running 
directly over the subway tunnel, follows the same timetable, except during Saturday to Sunday nights, when the tramway stops between 02:00 and 05:00, while the subway remains active. The subway system operates using $1200 \mathrm{~V} \mathrm{DC}$, while the tramway runs using a $750 \mathrm{~V} \mathrm{DC}$ electrification system.

This rather complex activity pattern allows easy comparison with the signal amplitude variations in the seismic data, in particular during the weekends. In the 20-40 $\mathrm{Hz}$ frequency band, the individual passage of trains can be identified in the seismic data recorded at about $150 \mathrm{~m}$ of the subway tunnel. From the inspection of the high-frequency seismic records, it can be observed that trains circulate for around $45 \mathrm{~min}$ after the end of the service (when the last train starts from the edges of the line) and that the train circulation starts around 20 min before the official time of start.

Surprisingly, the authors noted that the seismic energy variation at low frequencies $(8-50 \mathrm{mHz}, 20-125 \mathrm{~s}) \mathrm{mim}$ ics the subway time activity cycles. Figure 7 shows the seismic vertical component filtered within this frequency band for a period of 4 weeks, evidencing a time pattern matching the subway operating timetable. Although the low-frequency signal associated to subway activity could result from the deformation generated by the weight of the trains, Díaz et al. (2017) related its origin to the stray currents leaking to the Earth from the subway system that will generate a magnetic field disturbing the broadband sensor measurements.

\section{Collocated electric field measurements}

To test the hypothesis related to the effect of leakage currents, we have measured the electric field close to the site of the broad-band seismometer using electric dipoles. The acquisition system consisted of two orthogonal dipoles oriented parallel and perpendicular to subway and tramway lines (N20W, N70E). The distance between each dipole was close to $10 \mathrm{~m}$. Voltage measurements were sampled at a rate of 250 samples per second and stored in a datalogger equipped with a timing system based on GNSS signals. The acquisition

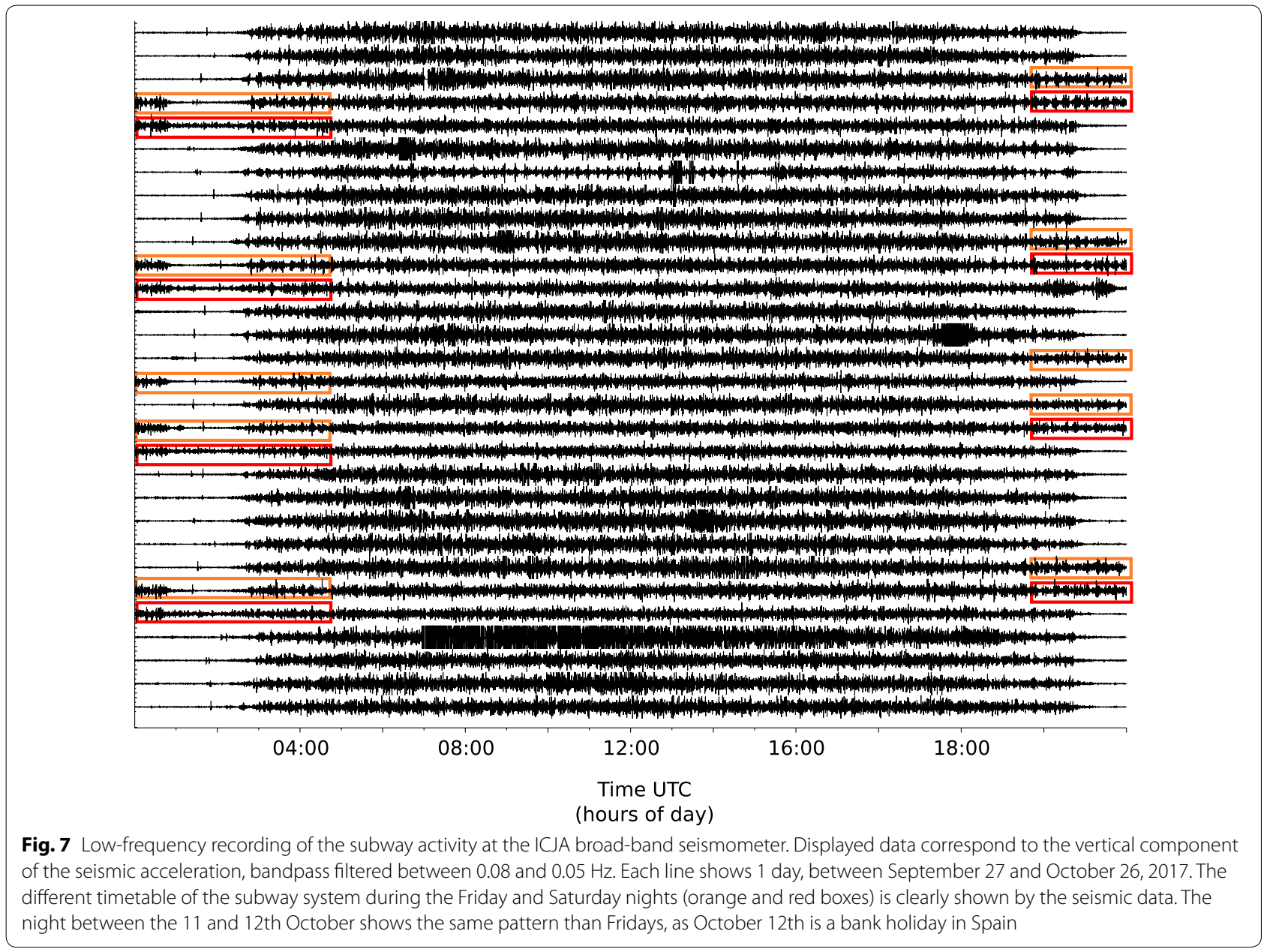


has been active in two periods; first during a week in June 2018 and then in a longer interval, from September to December 2018.

Figure 8 shows the electric field in one of the dipoles and the seismic acceleration in the $0.005-0.05 \mathrm{~Hz}$ band between the 18th and 23th October 2018. As it can be observed, the correlation between both signals is very high. The periods with significant electric field amplitude match the operation time of the transportation systems; during the nights of working days, both the electric field and the seismic data are close to zero during the period without subway activity (00:40-04:40, Local time). During Friday night, the time interval with low amplitudes is limited to $3 \mathrm{~h}$ long (00:00-3:00 UTC). Finally, during the Saturday to Sunday night, when the subway remains operative but the tramway not, the electric field above $0.01 \mathrm{~Hz}$ shows a minimum, only slightly higher than during week-day nights. It seems very clear that the amplitude variations for frequencies between 0.01 and $0.1 \mathrm{~Hz}$ in both the electric field and the seismic signal are correlated with the activity of the subway and tramway systems. This corroborates the hypothesis relating the seismic signals often observed at low frequencies to the variations of the magnetic field in the ground.
The corresponding spectrograms (Fig. 8c) confirm this interpretation and allow explaining some further details. The time variation pattern in seismic and electric data is very similar between 0.1 and $0.01 \mathrm{~Hz}$. The electric field data are dominated by signals related to subway activity till frequencies above $1 \mathrm{~Hz}$, while the seismic data above $0.1 \mathrm{~Hz}$ reflect the well-known variations related to the oceanic wave activity (i.e., Díaz 2016). Note that the large peak observed the 22nd October in the seismic data corresponds to the arrival of the seismic waves from a series of three earthquakes near Vancouver (Canada), with magnitudes 6.5, 6.8 and 6.5 and origin times $05: 39$, 06:16and 06:22 UTC.

Below $0.01 \mathrm{~Hz}$, the electric field variations have different behavior, with large peaks lasting $2-3 \mathrm{~h}$ appearing the Thursday, Saturday and Sunday during the first part of the day. From the inspection of the complete dataset, we have concluded that this low frequency signal appears in approx. $60 \%$ of the inspected days, most of the time during morning hours, but without any systematic pattern. We relate its origin to the use of electric devices close to the dipoles although this fact, not affecting the main discussion in this contribution, should be better studied.
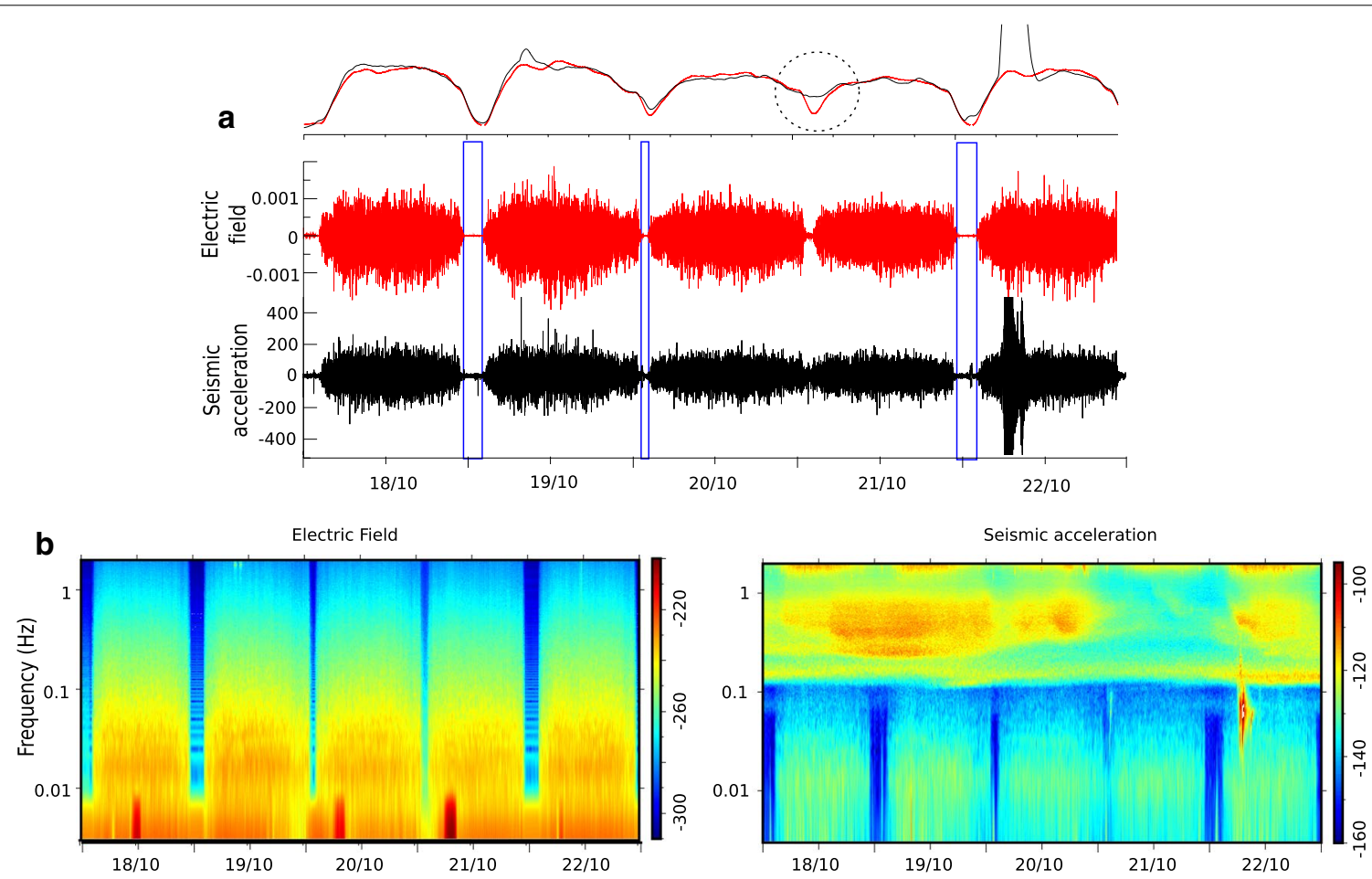

Fig. 8 Collocated electric and seismic signals related to subway and tramway activity. a Electric field $(\mathrm{V} / \mathrm{m}$, red line) and seismic vertical acceleration (nm/s $\mathrm{s}^{2}$, black line) filtered between 0.005 and $0.05 \mathrm{~Hz}$ recorded between October 18 and 23, 2018. Intervals without subway activity are marked with blue boxes. The upper panel shows the envelope of the same signals, downsampled to one sample every 20 min. Dotted circle highlights the difference between electric field and seismic data during the Saturday to Sunday night (see text). b Spectrograms of the seismic acceleration (right) and electric field (left) expressed in $\mathrm{dB}$ 
The relative minimum observed in the electric field during the Saturday-to-Sunday night suggests that the electric field measured on the surface is more sensitive to the leakage current from the tramway line (not operating in night hours) than to the leakage from the subway system (working continuously from Saturday morning to Sunday night). On the contrary, the amplitude variations recorded at the broad-band seismometer, installed in the basement of the building at approx. $3 \mathrm{~m}$ below the surface, nearly follow the activity of the subway system. Differences in the resistivity of the uppermost level of the subsoil can explain this observation, although additional observational and theoretical efforts are needed to explain the feature.

\section{Discussion and conclusions}

We have shown that broad-band seismometers are widely sensitive to variations in the Earth's magnetic field, both from natural and anthropogenic origins. Large SSC affects broad-band instruments worldwide, although large signals are better recorded at high latitudes and a reduced number of detections are observed in South America and Africa. We have documented that not only the SSC but the whole magnetic storm is also often recorded in seismic instruments. These observations confirm the first observations made by Wielandt (2002) and Forbriger (2007) and prove that the seismic detection of SSC is a worldwide phenomenon.

Our observations prove that magnetic signals are present in a large amount of different broad-band sensors, including STS-1, STS-2, Trillium 240 or Trillium 120, as well as post-hole and borehole instruments (Trillium 120 Post-Hole, Geotech KS-540000 Borehole). Therefore, the sensitivity of broad-band sensors to magnetic signals is a generic feature, affecting instruments with sensors measuring directly the vertical and the two horizontal components as well as those built following the symmetrical or Galperin arrangement, with three orthogonal sensors mounted obliquely, each of them sensing the same proportion of gravitational acceleration (e.g., Townsend 2014). We have also noted, analyzing data from 5 collocated sensors at station QSPA near the South Pole, that the relative variations in amplitude and polarity between the sensors remain stable during the investigated period, spanning from 2011 to 2019.

Analyzing regional seismic networks we can see how differences in amplitude and polarity do exist among close sites. Detections can be very different in the onset of sharpness, polarity, dominant frequency, or signal-tonoise ratio. To explain this, apart from the constructive peculiarities of each instrument, we must turn to the contribution of the telluric currents induced by the SSC signals, which depend on the local resistivity structure of the Earth's crust below them, including lateral heterogeneities, such as land-ocean interfaces. In this sense, we have shown that the areas with low electrical resistivity in the Ebro delta in NE Iberia seem to enhance the magnetic perturbations, allowing their systematic registration in seismic instruments.

In urban environments, we have shown that the leaking currents from public transportation systems as tramway or subway are detected by the broad-band sensors, dominating the spectra below $0.01 \mathrm{~Hz}$. To verify such origin, we have recorded simultaneously the seismic signal and the electric field and the results show a large correlation between both datasets in the frequency range 0.01$0.1 \mathrm{~Hz}$. It can be noted that the electric field measured at the surface is more sensitive to the leakage currents from the surface tramway, while the seismic sensor, located in the basement, approx. $3 \mathrm{~m}$ below the surface, seems more coincident with the subway activity. These low-frequency time variations in the seismic energy have previously reported by Green et al. (2017) at the London tube and by Sheen et al. (2009) near subway lines at Seoul and some more sparse worldwide sites, but their interpretation remained unclear. The collocated electric field measurements clearly support the hypothesis of a magnetic field alteration due to stray currents.

To provide a tentative explanation of the physical mechanisms that link these phenomena, we have to consider first the way a seismometer is constructed. In broad-band seismometers, the displacement of an inertial mass is detected by a capacitive displacement transducer, converted to an electric signal and transmitted to a feedback coil, which in turn restores the position on the mass applying a compensatory magnetic force. The electric current generating this compensatory force is proportional to the ground motion acceleration. To get a broad-band response, the sensors include a large capacitor acting as an integration stage and the final output is then a voltage proportional to ground velocity (Havskov and Alguacil 2016).

Broad-band seismometers need the use of materials with low thermal expansion coefficients for the suspension springs of the inertial mass. These springs are usually built using Elinvar, a nickel-iron-chromium or nickel-iron-molybdenum alloy (Guillaume 1967) which has the required small thermal coefficient but is sensitive to magnetic fields (Rau 1977). Forbriger (2007) presented seismograms showing clear signals corresponding to a couple of SSC events recorded at stations of the German Regional Seismic Network and proposed that the magnetic field disturbances affected the suspension springs of the inertial mass, resulting in apparent accelerations proportional to the variations of the magnetic field which, at low frequencies, can be larger than the accelerations 
due to mechanical accelerations generated by soil vibration. Alternatively, Kozlovskaya and Kozlovsky (2012) proposed that the origin of the magnetic signals generated by geomagnetic pulsations in seismic records has their origin in the feedback system of the sensor. Under this hypothesis, the geomagnetic field variations would result in an induced current modifying the electrical current flowing through the large capacitor and the feedback coil and resulting in apparent accelerations not related to ground motion.

It is well known that spurious signals related to electrical field variations not related to geomagnetic field variations are often observed in seismic recordings. Examples of this kind of signal include the anomalous apparent acceleration due to incremented electric current supply during hard disk access in the Quanterra baler recording system (Forbriger et al. 2010), the checking of sensor leveling in some OBS equipment (Stähler et al. 2017) or the spikes generated by poor filtering of charge regulators used to connect solar panels to the instrument battery (Havskov and Alguacil 2016). These effects are observed also in high-frequency geophones not equipped with either force-balance systems or sophisticated suspension springs. In these sensors, ground motion is measured by a wire coil moving within a magnetic field that produces an electrical signal proportional to ground velocity. Sudden variations in the electric field can modify this output voltage, leading to the observed spurious signals.

From the previous point, we propose a working hypothesis where the imprint of the magnetic signals in seismic records is mostly due to the effect of currents generated by the magnetic field variations that modify the current applied by the force-balance systems (broad-band instruments) or the voltage produced by the moving mass (geophones). This hypothesis would justify the enhancement of the signals in areas of high conductivity, where telluric currents induced by SSC events are expected to be relevant, and the low-frequency seismic signal detected during subway activity in urban environments and related to the effect of leakage currents. However, the fact that in the region of the South Atlantic Anomaly (SAA), where the intensity of the main magnetic field is much lower, coincides with the region where the magnetic signals are more difficult to be observed in seismic stations, leads us to think that the magnetization of the spring effects should not be disregarded. Forbriger (2007) suggested that Earth's permanent field adds a magnetization bias to the overall spring magnetization. It looks like only seismometers located in regions where the sum of the constant magnetization plus that due to field variations exceeds a threshold are sensitive to them. Therefore, for the events analyzed in this study, seismometers located within the SAA would hardly reach the spring magnetization that triggers the effect. A further experimental and theoretical effort is needed to fully understand how these processes result in the generation of signals related to magnetic events in seismometers.

We have seen that the SSC signals recorded on broad-band seismometers are affected by multiple factors depending on each sensor or specific details of its location, which makes it difficult to use them to obtain quantitative measurements of these magnetic features. However, as pointed by Forbriger et al. (2010), it is possible to calibrate the seismometers response to magnetic field using a nearby $(100 \mathrm{~s} \mathrm{~km})$ magnetometer. The time stability of the signals recorded by the different seismic sensors at the South Pole station seems to confirm the feasibility of this approach. Although a worldwide magnetic network is nowadays available, the number of available broad-band seismic stations is larger, in the order of few hundreds. Therefore, the seismic recordings could be used as a complementary tool to monitor the occurrence of magnetic field disturbances in areas far from magnetic observatories.

\section{Supplementary information}

Supplementary information accompanies this paper at https://doi. org/10.1186/s40623-020-01236-9.

Additional file 1: Figure S1. Representative SSC-related seismic signals at QSPA station (South Pole). Each panel shows the acceleration records of SSC events between 2011 and 2018, at the different sensors installed in the same site, all of them represented using a common amplitude scale $\left(\mathrm{m} / \mathrm{s}^{2}\right)$. Note that, although the amplitude of each event are very different, the relative amplitude and polarity differences between sensors remain stable.

\section{Abbreviations}

SC: Sudden Commencement; SSC: Sudden Strom Commencements; GIC: Geomagnetically induced currents; H: Horizontal magnetic intensity.

\section{Acknowledgements}

We want to acknowledge the ORFEUS EIDA (http://www.orfeus-eu.org/ data/eida/) and the FDSN data services (https://www.fdsn.org/services/) to provide easy access to seismic data and to the different seismic networks making available its data. Data collected at magnetic observatories have been used as a supporting information in this contribution. We thank the national institutes that support them and INTERMAGNET for promoting high standards of magnetic observatory practice (http://www.intermagnet.org). We also thank to Service of Rapid Magnetic Variations (http://www.obsebre.es) for its effort to provide reliable lists of SSC events. We want also to acknowledge fruitful discussions on the characteristics of the SAA anomaly with Dr. F.J. Pavón-Carrasco.

\section{Authors' contributions}

$J D, J J C, J M T$, and $J L$ contributed to the conception and design of the project. MR organized the database of the seismic data and helped in their processing and interpretation. JL, AM, and PQ contributed to the acquisition of the electric field measurements and their interpretation. JD wrote the first draft of the manuscript and figures. All authors contributed to manuscript revision. All authors read and approved the final manuscript. 


\section{Funding}

This contribution has received financial support from the Generalitat de Catalunya Grants 2017SGR1022 and 2017SGR596. The contribution of JJC and JMT has been supported by Spanish Project CGL2017-82169-C2-1-R (AEI/ FEDER, UE), and contributions of JL, AM, and PQ, by CGL2017-82169-C2-2-R (AEI/FEDER, UE)

\section{Availability of data and materials}

The seismic datasets analyzed for this study can be found in the ORFEUS Data Center (http://www.orfeus-eu.org/fdsnws/dataselect/1/) and in the Institut Cartográfic i Geológic de Catalunya repository (http://ws.icgc.cat/fdsnws/ dataselect/1/). Magnetic data series are available from the INTERMAGNET webpage (https://www.intermagnet.org/data-donnee/download-eng.php). Sudden Storm Commencement list are available at http://www.obsebre.es/ en/rapid.

\section{Ethics approval and consent to participate}

Not applicable.

\section{Consent for publication}

Not applicable.

\section{Competing interests}

The authors declare that the research was conducted in the absence of any commercial or financial relationships that could be construed as the potential competing interests.

\section{Author details}

${ }^{1}$ Geosciences Barcelona, CSIC, c. Solé Sabarís sn, 08028 Barcelona, Spain

${ }^{2}$ Observatori de I'Ebre, (OE), CSIC - Univ. Ramon Llull, Horta Alta, 38, 43520 Roquetes, Spain. ${ }^{3}$ Institut Geomodels, Dept, Dinàmica de la Terra i de I'Oceà, Facultat de Ciències de la Terra, Universitat de Barcelona, Martí i Franquès, s/n, 08028 Barcelona, Spain.

Received: 10 April 2020 Accepted: 17 July 2020

Published online: 29 July 2020

\section{References}

Albuquerque Seismological Laboratory (ASL)/USGS (1988): Global Seismograph Network-IRIS/USGS. International Federation of Digital Seismograph Networks. Dataset/Seismic Network. https://doi.org/10.7914/sn/iu

Araki T (1977) Global structure of geomagnetic sudden commencements. Planet Space Sci 25(4):373-384. https://doi.org/10.1016/00320633(77)90053-8

Araki T (1994) A physical model of the geomagnetic sudden commencement. In: Engebretson MJ, Takahashi K, Scholer M (eds) Solar wind sources of magnetospheric ultra-low-frequency waves. AGU, Washington, DC

Bellmunt F, Gabàs A, Macau A, et al (2018) EBRO delta geometry and structure characterization using the electrical resistivity imaging method. In: 24th European Meeting of Environmental and Engineering Geophysics. https ://doi.org/10.3997/2214-4609.201802517

Bravin E, Brun G, Dehning B et al (1998) The influence of train leakage currents on the LEP dipole field. Nucl Instrum Methods Phys Res Sect A Accel Spectrom Detect Assoc Equip 417:9-15. https://doi.org/10.1016/s0168 -9002(98)00020-5

Curto JJ, Araki T, Alberca LF (2007) Evolution of the concept of Sudden Storm Commencements. Earth Planets Space 59:i-xii https://doi.org/10.1186/ BF03352059

De Pádua MB, Bologna MS, Padilha AL (2002) Disturbances on magnetotelluric data due to electrified railway. Earth Planets Space 54:591-596. https:// doi.org/10.1186/BF03353047

Díaz J (2016) On the origin of the signals observed across the seismic spectrum. Earth-Sci Rev. https://doi.org/10.1016/j.earscirev.2016.07.006

Díaz J, Ruiz M, Sánchez-Pastor PS, Romero P (2017) Urban seismology: on the origin of earth vibrations within a city. Sci Rep. https://doi.org/10.1038/ s41598-017-15499-y

Forbriger T (2007) Reducing magnetic field induced noise in broad-band seismic recordings. Geophys J Int 169:240-258. https://doi.org/10.1111/ j.1365-246x.2006.03295.x
Forbriger T, Widmer-Schnidrig R, Wielandt E, Hayman M, Ackerley N (2010) Magnetic field background variations can limit the resolution of seismic broad-band sensors. Geophys J Int 183:303-312. https://doi.org/10.1111/ j.1365-246x.2010.04719.x

GEOFON Data Centre (1993) GEOFON seismic network. Deutsches GeoForschungsZentrum GFZ. https://doi.org/10.14470/tr560404

Gilbert JL (2014) Simplified techniques for treating the ocean-land interface for geomagnetically induced electric fields. In: Proceedings of the IEEE international symposium on electromagnetic compatibility. IEEE, Raleigh, pp 566-569

Green DN, Bastow ID, Dashwood B, Nippress SEJ (2017) Characterizing broadband seismic noise in Central London. Seismol Res Lett 88:113-124. https ://doi.org/10.1785/0220160128

Guillaume CE (1967) Invar and elinvar. Nobel lectures, physics 1901-1921, vol 3. Elsevier, Amsterdam, pp 444-473

Havskov J, Alguacil G (2016) Instrumentation in earthquake seismology, 2nd edn. Springer, Berlin

Institut De Physique Du Globe De Paris (IPGP), \& Ecole Et Observatoire Des Sciences De La Terre De Strasbourg (EOST) (1982) GEOSCOPE, French Global Network of broad band seismic stations. Institut de Physique du Globe de Paris (IPGP). https://doi.org/10.18715/geoscope.g

Institut Cartogràfic i Geològic de Catalunya (2000) Catalan seismic network. International Federation of Digital Seismograph Networks. Other/Seismic Network. https://doi.org/10.7914/sn/ca

Khabarova O, Pilipenko V, Engebretson MJ, Rudenchik E (2006) Solar wind and interplanetary magnetic field features before magnetic storm onset. Proc Int Conf Substorms 8:1-6

Kozlovskaya E, Kozlovsky A (2012) Influence of high-latitude geomagnetic pulsations on recordings of broadband force-balanced seismic sensors. Geosci Instrum Methods Data Syst 1:85-101. https://doi.org/10.5194/ gi-1-85-2012

Lowes FJ (2009) DC railways and the magnetic fields they produce-the geomagnetic context. Earth Planets Space. https://doi.org/10.1186/bf033 52944

Maeda H, Sakurai K, Ondoh T, Yamamoto M (1962) Solar terrestrial relationships during the IGY and IGC. Ann Geophys 18:305-333

Mapa geològic de Catalunya 1:100000; Comarques del Ebre (2003) Institut per al Desenvolupament de les Comarques de l'Ebre, Institut Cartogràfic de Catalunya. Dipòsit Legal B 2 038-2003

Marsal S, Torta JM, Segarra A, Araki T (2017) Use of spherical elementary currents to map the polar current systems associated with the geomagnetic sudden commencements on 2013 and 2015 St. Patrick's Day storms. J Geophys Res Space Phys 122:194-211. https://doi.org/10.1002/2016j a023166

NCEl Geomagnetic Modeling Team and British Geological Survey (2019) World Magnetic Model 2020. NOAA National Centers for Environmental Information. https://doi.org/10.25921/11v3-da71, 2020, Accessed 30 May 2020

Ngwira CM, Pulkkinen AA, Bernabeu E et al (2015) Characteristics of extreme geoelectric fields and their possible causes: localized peak enhancements. Geophys Res Lett 42:6916-6921. https://doi.org/10.1002/2015g 1065061

Nishida A (1978) Geomagnetic diagnosis of the magnetosphere. Springer, New York, pp 1-37

Olsen N, Hulot G, Sabaka TJ (2007) The present field. Treatise Geophys 5:33-75. https://doi.org/10.1016/b978-044452748-6.00087-0

Oughton EJ, Skelton A, Horne RB et al (2017) Quantifying the daily economic impact of extreme space weather due to failure in electricity transmission infrastructure. Space Weather 15:65-83. https://doi.org/10.1002/2016s w001491

Palanques A, Guillén J (1998) Coastal changes in the Ebro delta: natural and human factors. J Coast Conserv 4:17-26

Park W, Lee J, Yi Y et al (2015) Storm sudden commencements without interplanetary shocks. J Astron Space Sci 32:181-187. https://doi.org/10.5140/ jass.2015.32.3.181

Pirjola R (2013) Practical model applicable to investigating the coast effect on the geoelectric field in connection with studies of geomagnetically induced currents. Adv Appl Phys 1:9-28. https://doi.org/10.12988/ aap. 2013.13002

Pulkkinen A (2015) Geomagnetically induced currents modeling and forecasting. Space Weather 13:734-736. https://doi.org/10.1002/2015sw001316 
Rau G (1977) Metallische Verbundwerkstoffe. WerkstofftechnischeVerlagsgesellschaft m.b.H, Karlsruhe

San Fernando Royal Naval Observatory (ROA), Universidad Complutense De Madrid (UCM), Helmholtz-Zentrum Potsdam Deutsches GeoForschungsZentrum (GFZ), Universidade De Evora (UEVORA, Portugal), \& Institute Scientifique Of RABAT (ISRABAT, Morocco) (1996) The Western Mediterranean BB seismic Network. Deutsches GeoForschungsZentrum GFZ. https:// doi.org/10.14470/jz581150

Scripps Institution of Oceanography (1986): Global Seismograph Network-IRIS/ IDA. International Federation of Digital Seismograph Networks. Dataset/ Seismic Network. https://doi.org/10.7914/sn/ii

Segarra A, Curto JJ (2013) Automatic detection of sudden commencements using neural networks. Earth Planets Space 65:791-797. https://doi. org/10.5047/eps.2012.12.011

Sheen DH, Shin JS, Kang TS, Baag CE (2009) Low frequency cultural noise. Geophys Res Lett 36:1-5. https://doi.org/10.1029/2009gl039625

Stähler SC, Sigloch K, Hosseini K et al (2017) Performance report of the RHUMRUM ocean bottom seismometer network around La Réunion, western Indian Ocean. Adv Geophys 41:43-63. https://doi.org/10.5194/adgeo $-41-43-2016$

Tanbo T, Sakai H, Nagao T (2003) A study of geoelectric potential change caused by rail leak current observed of Ohtawa, Gifu, Japan. Electr Eng
Japan 143:1-10. https://doi.org/10.1002/eej.10142 (English TransI Denki Gakkai Ronbunshi)

Torta JM, Serrano L, Regué JR, Sánchez AM (2012) Geomagnetically induced currents in a power grid of northeastern Spain. Space Weather 10:1-11. https://doi.org/10.1029/2012sw000793

Torta JM, Marcuello A, Campanyà J, et al (2017) Improving the modeling of geomagnetically induced currents in Spain. 1-13. https://doi. org/10.1002/2017sw001628.received

Townsend B (2014) Symmetric triaxial seismometers. In: Beer M, Kougioumtzoglou I, Patelli E, Au IK (eds) Encyclopedia of earthquake engineering. Springer, Berlin. https://doi.org/10.1007/978-3-642-36197-5_194-1

Wang C, Li W, Wang Y, Wang Y, Xu S, Fan M (2018) Stray current distributing model in the subway system: a review and outlook. Int J Electrochem Sci 13:1700-1727. https://doi.org/10.20964/2018.02.16

Wielandt E (2002) Seismometry. In: Lee WHK, Kanamori H, Jennings PC, Kisslinger C (eds) International handbook of earthquake and engineering seismology, vol A. Academic Press, Amsterdam, pp 283-304

\section{Publisher's Note}

Springer Nature remains neutral with regard to jurisdictional claims in published maps and institutional affiliations.

\section{Submit your manuscript to a SpringerOpen ${ }^{\odot}$ journal and benefit from:}

- Convenient online submission

- Rigorous peer review

- Open access: articles freely available online

- High visibility within the field

- Retaining the copyright to your article

Submit your next manuscript at $\boldsymbol{\nabla}$ springeropen.com 